\title{
Vitamin E infused highly cross-linked cemented cups in total hip arthroplasty show good wear pattern and sta- bilize satisfactorily: a randomized, controlled RSA trial with 5-year follow-up
}

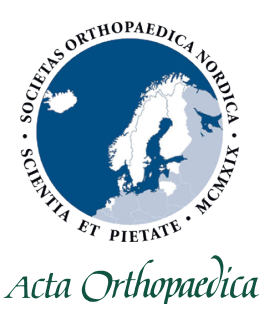

\author{
Halldor BERGVINSSON, Vasilis ZAMPELIS, Martin SUNDBERG, Jon TJÖRNSTRAND, \\ and Gunnar FLIVIK
}

Department of Orthopedics, Skåne University Hospital, Clinical Sciences, Lund University, Lund, Sweden

Correspondence: halldor.bergvinsson@med.lu.se

Submitted 2021-10-25. Accepted 2021-12-23.

Background and purpose - Vitamin E infused highly cross-linked polyethylene (VEPE) was introduced in order to enhance oxidative resistance in highly cross-linked polyethylene cups in total hip arthroplasty (THA). We have, with a follow-up of 5 years, evaluated wear characteristics of 2 identically designed cemented cups with the only difference being the material, VEPE or ultra-high molecular weight polyethylene (UHMWPE). Furthermore, we report cup migration and clinical outcome.

Patients and methods - 48 patients with primary osteoarthritis were randomized to either UHMWPE or VEPE cups. Patients were followed with radiostereometric analysis (RSA) from the first postoperative day, at 3 months, 1,2, and 5 years as well as with hip-specific outcome questionnaires.

Results - At 3 months the mean proximal head penetration for UHMWPE was $0.07 \mathrm{~mm}(95 \%$ CI $0.03-0.11)$ and for VEPE $0.06 \mathrm{~mm}(-0.01$ to 0.13$)$. Thereafter, there was a continuous annual wear of $0.08 \mathrm{~mm} /$ year, up to $0.46 \mathrm{~mm}$ $(0.36-0.57)$ at 5 years, for the UHMWPE cup. The VEPE cup showed low annual wear of $0.01 \mathrm{~mm} /$ year, up to $0.09 \mathrm{~mm}$ $(0.02-0.16)$ at 5 years. In the first 3 months the UHMWPE cup migrated cranially $0.08 \mathrm{~mm}(0.03-0.13)$ whereas the VEPE cup migrated $0.17 \mathrm{~mm}(0.10-0.24)$, Thereafter, they showed similar migration patterns with stabilization between 2 and 5 years up to $0.21 \mathrm{~mm}(0.04-0.39)$ and $0.24 \mathrm{~mm}(0.13-$ $0.36)$ respectively. The HOOS remained good up to 5 years, and no cup was revised.

Interpretation - Compared with otherwise identical UHMWPE cups the cemented VEPE cup shows statistically significant reduction of wear up to 5 years and both cup types stabilize well with good clinical outcome.
Since the introduction of highly cross-linked polyethylene (HXLPE), it has proven itself superior to ultra-high molecular weight polyethylene (UHMWPE) with lower wear and good implant survival $(1,2)$. However, these results have been challenged by oxidation and wear. Oxidation of the HXLPE results in decreased crosslink density, leading to increased wear with short-term clinical failures after gamma sterilization in air or long-term shelf ageing in air (3). To address this problem manufacturers developed strategies to improve oxidation resistance and wear reduction. Annealing resulted in a product containing elevated residual free radicals with the potential to oxidize in vivo, whereas remelting resulted in undetectable amounts of free radicals but reduced the crystallinity of the polyethylene and lowered the material properties (4).

In order to provide enhanced oxidation resistance, without compromising the fatigue strength of HXLPE, the practice of Vitamin-E ( $\alpha$-tocopherol) infusion in highly cross-linked polyethylene (hereafter called VEPE) was introduced (5). The use of VEPE liners in total hip arthroplasty (THA), with cementless cups, has been studied in clinical trials with low wear at short and mid-term follow-ups (6-10), indicating that VEPE is a promising alternative in THA although longer follow-up is needed. However, there has been only 2 studies on VEPE evaluating cemented cups, both showing similar results to those for the uncemented THA $(11,12)$.

In a randomized trial we primarily determined the wear properties of 2 identically designed cemented cups, up to 5 years, with the only difference being the material: VEPE or UHMWPE. Wear was measured with the use of radiostereometric analysis (RSA). Secondarily we compared the migration pattern of these cups as well as clinical outcome, measured with a hip osteoarthritis outcome score (HOOS) and a health-related quality of life score (EQ5D). 
Table 1. Patient characteristics

\begin{tabular}{llll}
\hline Variables & $\begin{array}{c}\text { UHMWPE } \\
\mathrm{n}=24\end{array}$ & $\begin{array}{c}\text { VEPE } \\
\mathrm{n}=24\end{array}$ & $\begin{array}{c}\text { Total } \\
\mathrm{n}=48\end{array}$ \\
\hline Age (range) & $72(58-83)$ & $71(62-81)$ & $71(58-83)$ \\
Female sex & 18 & 19 & 37 \\
BMI (SD) & $25(3.6)$ & $27(4.7)$ & $26(4.2)$ \\
\hline
\end{tabular}

\section{Patients and methods}

\section{Trial design and patients}

This is a randomized control trial, conducted at Skåne University Hospital, with surgery performed between January 2014 and June 2015. 48 patients with mean age 71 years (58-82) were included. All had primary hip osteoarthritis (OA) and were graded Charnley class A or B (Table 1).

Exclusion criteria were patients with marked bone loss, Parkinson's disease, immunosuppressive disease and/or therapy, BMI $<16$ or $>40$, ASA IV-V, previous surgery on the hip, THA on the contralateral side within the last 6 months, active infection, dementia, malignant disease, rheumatoid arthritis, or alcohol abuse. Further exclusion criteria were patients considered better suited to an uncemented THA, based mainly on age ( $<55$ years) and bone quality considerations (type A femur).

1 patient in the VEPE group had an insufficient amount of tantalum markers in the cup, thus being ineligible for RSA analysis, and was excluded from the trial. At 60 months, 2 patients, 1 from each group, declined follow-up due to nonhip-related illness and 1 patient from the VEPE group had died. Thus, 23 patients from the PE group and 21 patients from the VEPE group were eligible for analysis after 5 years (Figure 1).

\section{Surgery}

Surgery was performed by 3 experienced hip surgeons (GF, MS, JT) with a posterolateral approach at Skåne University Hospital, Sweden. All patients received a Sirius cemented stem (Biomet Orthopedics, Warsaw, IN, USA). Statistics software was used to create a blocked randomization and closed numbered envelopes were opened during surgery to decide whether the patient should have an Exceed ABT cemented cup (Biomet Orthopedics, Warsaw, IN, USA) made of either UHMWPE (ArCom) or VEPE (E1 Antioxidant Infused technology). All patients received a $32 \mathrm{~mm}$ metal $(\mathrm{CoCr})$ femoral head. Refobacin bone cement (Biomet) was used, and the implants inserted according to the manufacturer's recommendations. Both the patients and the RSA analyst were blinded to the type of intervention.

The UHMWPE is made of GUR1050 resin and manufactured in a hot-isostatic compression molding process.
The VEPE is based on the UHMWPE barstock and is machined, packaged, and gamma irradiated to a dose of 100 kGy (10 Mrad), in order to cross-link the polymer chains. After irradiation, the parts are infused with vitamin E. The polyethylene is then machined into the final geometry and gamma sterilized.

\section{Clinical assessment}

A self-administered Hip Disability and Osteoarthritis Outcome Score (HOOS), and a health-related quality of life score (EQ5D) was completed before surgery and at 12,24 , and 60 months.

\section{Radiostereometric analysis}

RSA examinations were performed according to the guidelines for standardization for RSA (13). During surgery, 8-9 tantalum beads $(0.8 \mathrm{~mm}$ diameter $)$ were inserted into the periacetabular bone; an additional 5-6 tantalum beads were inserted into the peripheral surface of the cup. All patients underwent conventional radiographic examination and a reference RSA examination on the 1 st postoperative day. The patients were followed with RSA and clinical examinations at 3, 12, 24, and 60 months, with a time tolerance of $\pm 5 \%$. All patients had a double examination at the 1st postoperative examination to calculate the precision value of the examination (Table 2, see Supplementary data).

The center of the femoral head in relation to the segment made up of the tantalum markers in the cup was used for the wear analysis. The tantalum markers in the cup and periacetabular bone were used to form segments, which in turn were used for the cup migration analysis. Proximal head penetration (Y-translation) and 3D penetration were selected as primary 
Table 3. Wear measured as translation of femoral head in ( $\mathrm{mm})$. Values are mean $(95 \% \mathrm{Cl})$

\begin{tabular}{ccccc}
\hline Axis & Months & UHMWPE & VEPE & p-value a \\
\hline Y & 3 & $0.07(0.03$ to 0.11$)$ & $0.06(-0.01$ to 0.13$)$ & 0.6 \\
& 12 & $0.14(0.09$ to 0.20$)$ & $0.07(0.00$ to 0.13$)$ & \\
& 24 & $0.23(0.17$ to 0.30$)$ & $0.07(0.01$ to 0.14$)$ & \\
& 60 & $0.46(0.36$ to 0.57$)$ & $0.09(0.02$ to 0.16$)$ & $<0.01$ \\
3D & 3 & $0.23(0.15$ to 0.30$)$ & $0.26(0.13$ to 0.39$)$ & 0.8 \\
& 12 & $0.42(0.13$ to 0.71$)$ & $0.28(0.14$ to 0.43$)$ & \\
& 24 & $0.50(0.21$ to 0.79$)$ & $0.29(0.15$ to 0.43$)$ & \\
& 60 & $0.68(0.42$ to 0.95$)$ & $0.32(0.17$ to 0.47$)$ & $<0.01$
\end{tabular}

a The $p$-value indicates the differences in slope between the 2 groups as calculated with a piecewise linear mixed effects model, with a knot at 3 months thus comparing 0 to 3 months and 3 months to 5 years, respectively.

effect variables for wear analysis. In the secondary outcome, change in proximal cup migration (Y-translation) and inclination (Z-rotation) was added for the cup analysis.

\section{Statistics}

Power analysis was performed based on previously published RSA data on stems and cups. Assuming that the true difference of head penetration at 2 years is $0.1 \mathrm{~mm}$ with a common $\mathrm{SD}$ of $0.1,21$ patients in each group would yield a power of $90 \%$ to find a statistically significant difference between the groups, using a significance level of 0.05 . To cover possible dropouts, 24 patients were included in each group.

Continuous variables are presented using mean and SD or range, and categorical variables are presented using counts and percentages. A significance level of 0.05 was used for all statistical tests and 95\% confidence intervals (CI).

Wear over time was analyzed using a piecewise linear mixed-effect model with a knot (breaking point) at 3 months after surgery where a clear pattern change from creep to deformation has been shown in an earlier study (14). The models included 3 fixed effects: group, time starting from surgery and time starting from 3 months after surgery, and 2 interaction terms between group and the time variables. Subject was included as a random effect. These models gave the opportunity to compare the wear slopes before and after the breaking point between the 2 cup types. The primary endpoint could therefore be defined as the slope of the wear during the first 5 years estimated from observations at 3 months, 1 year, 2 years, and 5 years. Before performing the actual analyses, data was reviewed to confirm the assumption that the breaking point was at 3 months after surgery.

The clinical outcome data was analyzed using a MannWhitney U-test for comparison between groups.

\section{Ethics, registration, data sharing, funding, and poten- tial conflicts of interest}

The trial, which includes an RSA evaluation on the femoral side, was approved by the Ethics Committee of Lund Uni-

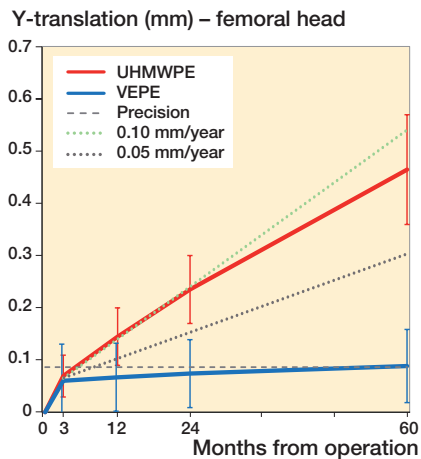

Figure 2. Y-translation of the femoral head for UHMWPE and VEPE cups with $95 \% \mathrm{Cl}$ bars. Proposed wear thresholds in the literature of $0.1 \mathrm{~mm} /$ year and 0.05 $\mathrm{mm} /$ year are shown for easier visualization.

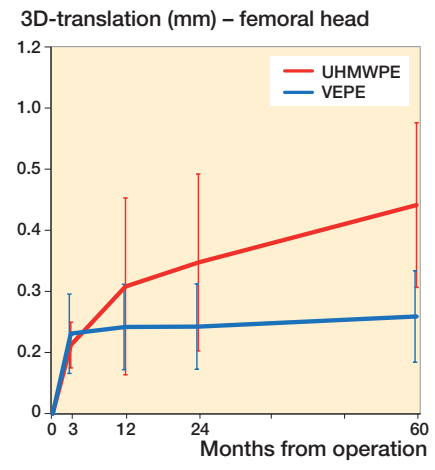

Figure 3. 3D-translation of the femoral head in relation to the cups for UHMWPE and VEPE cups with $95 \% \mathrm{Cl}$ bars. versity, Sweden (Dnr 2013/801). Written informed consent was obtained from all patients to participate in the trial. The trial was carried out according to the Helsinki Declaration of 1975, as revised in 2000, and registered in ClinicalTrials.gov (identifier: NCT02307331). The data sharing plan was written on DMPRoadmap at Lund University. Complimentary data is available on reasonable request.

Zimmer Biomet has been financially sponsoring part of the RSA examinations but has had no part in the analysis or interpretation of data. The authors have no conflicts of interest related to the trial.

\section{Results}

\section{RSA}

Both cup types showed an initial deformation caused by the femoral head, also called creep, during the first 3 months. The mean proximal head penetration (Y-translation) for the UHMWPE was $0.07 \mathrm{~mm}$ and for the VEPE $0.06 \mathrm{~mm}$ after this first deformation phase. Thereafter, the UHMWPE had continuous wear throughout the trial period and at 5 years had a total Y-translation of $0.46 \mathrm{~mm}$, corresponding to an annual wear rate of $0.08 \mathrm{~mm} /$ year. Between 3 months and 5 years the VEPE continued to show low wear values and at 5 years had a total Y-translation of $0.09 \mathrm{~mm}$ with annual wear rate of $0.01 \mathrm{~mm} / \mathrm{year}$. The difference in mean wear between groups at 2 and 5 years was statistically significant (Table 3 and Figure 2).

The total 3D penetration was $0.23 \mathrm{~mm}$ for the UHMWPE and $0.26 \mathrm{~mm}$ for the VEPE group after 3 months. Similar to the Y-translation, the 3D measured wear steadily continued for the UHMWPE, yielding $0.68 \mathrm{~mm}$ after 5 years. In contrast, the VEPE showed a low wear value of $0.32 \mathrm{~mm}$ after 5 years. This results in an annual wear rate of $0.1 \mathrm{~mm} /$ year for the UHMWPE and $0.01 \mathrm{~mm} / \mathrm{year}$ for the VEPE (Figure 3). 
Table 4. Cup migration. Values are mean $(95 \% \mathrm{Cl})$

\begin{tabular}{|c|c|c|c|}
\hline Axis/Months & UHMWPE & VEPE & -value ${ }^{a}$ \\
\hline \multicolumn{4}{|c|}{ Translation (mm) } \\
\hline \multicolumn{4}{|c|}{ X-axis, medial (+) or lateral (-) } \\
\hline 3 & $0.01(-0.02$ to 0.04$)$ & $0.06(-0.01$ to 0.14$)$ & 0.3 \\
\hline 12 & $-0.01(-0.09$ to 0.07$)$ & $0.07(-0.05$ to 0.18$)$ & \\
\hline 24 & $0.01(-0.06$ to 0.07$)$ & $0.09(-0.04$ to 0.22$)$ & \\
\hline 60 & $0.02(-0.09$ to 0.12$)$ & $0.16(-0.02$ to 0.35$)$ & 0.1 \\
\hline \multicolumn{4}{|c|}{ Y-axis, proximal (+) or distal (-) } \\
\hline 3 & 0.08 (0.03 to 0.13$)$ & $0.17(0.10$ to 0.24$)$ & 0.06 \\
\hline 12 & 0.14 (0.06 to 0.22$)$ & $0.22(0.13$ to 0.32$)$ & \\
\hline 24 & 0.17 (0.08 to 0.26$)$ & $0.24(0.15$ to 0.33$)$ & \\
\hline 60 & 0.21 (0.04 to 0.39$)$ & $0.24(0.13$ to 0.36$)$ & 0.3 \\
\hline \multicolumn{4}{|c|}{ Z-axis, anterior $(+)$ or posterior $(-)$} \\
\hline 3 & 0.06 (0.00 to 0.13$)$ & $0.02(-0.05$ to 0.09$)$ & 0.3 \\
\hline 12 & $0.04(-0.22$ to 0.10$)$ & $-0.01(-0.07$ to 0.05$)$ & \\
\hline 24 & $0.02(-0.04$ to 0.09$)$ & $-0.01(-0.09$ to 0.06$)$ & \\
\hline 60 & 0.01 ( -0.02 to 0.22$)$ & $0.05(-0.03$ to 0.13$)$ & 0.9 \\
\hline \multicolumn{4}{|c|}{ Rotation $\left({ }^{\circ}\right)$} \\
\hline \multicolumn{4}{|c|}{$\mathrm{X}$-axis, anterior $(+)$ or posterior $(-)$} \\
\hline 3 & $0.09(-0.03$ to 0.22$)$ & $0.07(-0.08$ to 0.23$)$ & 0.7 \\
\hline 12 & $0.10(-0.13$ to 0.32$)$ & $0.13(-0.03$ to 0.29$)$ & \\
\hline 24 & $0.08(-0.09$ to 0.26$)$ & $0.11(-0.09$ to 0.30$)$ & \\
\hline 60 & $-0.02(-0.35$ to 0.31$)$ & $0.29(0.04$ to 0.55$)$ & 0.01 \\
\hline \multicolumn{4}{|c|}{ Y-axis, anteversion (+) or retroversion $(-)$} \\
\hline 3 & $-0.07(-0.18$ to 0.04$)$ & $-0.11(-0.26$ to 0.05$)$ & 0.9 \\
\hline 12 & $-0.11(-0.37$ to 0.15$)$ & $-0.05(-0.21$ to 0.10$)$ & \\
\hline 24 & $-0.10(-0.29$ to 0.08$)$ & $-0.13(-0.29$ to 0.02$)$ & \\
\hline 60 & $-0.01(-0.29$ to 0.26$)$ & $-0.11(-0.35$ to 0.12$)$ & 0.5 \\
\hline \multicolumn{4}{|c|}{ Z-axis, decreased $(+)$ and increased inclination $(-)$} \\
\hline 3 & $-0.07(-0.16$ to 0.03$)$ & $-0.10(-0.32$ to 0.12$)$ & 0.9 \\
\hline 12 & $-0.25(-0.54$ to 0.04$)$ & $-0.17(-0.48$ to 0.14$)$ & \\
\hline 24 & $-0.20(-0.40$ to 0.01$)$ & $-0.08(-0.44$ to 0.27$)$ & \\
\hline 60 & $-0.24(-0.55$ to 0.07$)$ & $-0.03(-0.50$ to 0.44$)$ & 0.2 \\
\hline
\end{tabular}

a See Table 3

During the first 3 months the UHMWPE cup migrated 0.08 $\mathrm{mm}$ cranially (Y-translation) whereas the VEPE cup migrated $0.17 \mathrm{~mm}$. There was a slight continuous migration of both cups up to 2 years, but after that they had stabilized and at 5 years they showed a total Y-translation of $0.21 \mathrm{~mm}$ and 0.24 $\mathrm{mm}$, respectively, for the UHMWPE and VEPE cups. The UHMWPE cup had initial Z-rotation of $-0.07^{\circ}$ and $-0.10^{\circ}$ for the VEPE cup. During the trial period the Z-rotation increased negatively to $-0.24^{\circ}$ for the UHMWPE whereas the VEPE cups showed positive rotation to $-0.03^{\circ}$ at 5 years (Table 4 and Figures 4 and 5).

1 patient in the UHMWPE group had a noticeable osteolytic zone in DeLee and Charnley Zone 1 on the 1st postoperative radiography. This patient had an initial Y-migration of the cup of $0.39 \mathrm{~mm}$ after 3 months and had a steady increase in Y-migration during the trial period with total Y-migration of $1.76 \mathrm{~mm}$. So far, however, this cup has not been revised. No other cup in the trial showed signs of radiological or clinical loosening.

\section{Clinical outcome}

HOOS and EQ5D outcome was similar for both groups preoperatively as well as at 12,24 , and 60 months with no statisti-

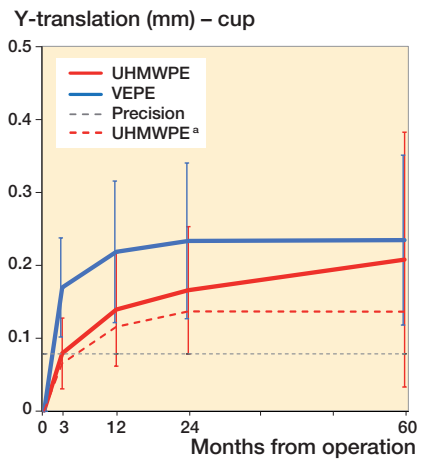

Figure 4. Y-translation of the UHMWPE and VEPE cups with $95 \% \mathrm{Cl}$ bars. a The dashed UHMWPE line represents the mean values when the outlying patient has been excluded.

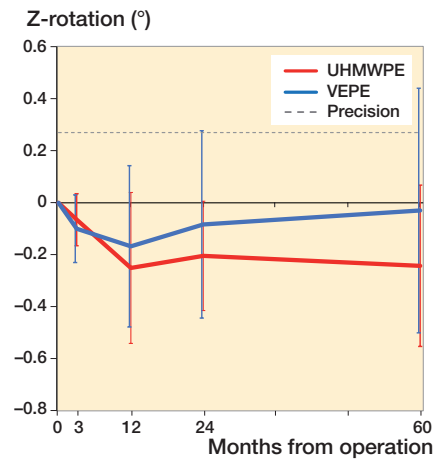

Figure 5. Z-rotation of the UHMWPE and VEPE cups with $95 \% \mathrm{Cl}$ bars. Positive rotation indicates decreased inclination, whereas negative rotation indicates increased inclination. cally significant difference between groups. As expected, the scores improved compared with preoperatively and remained good up to 5 years (Figures 6 and 7, see Supplementary data).

\section{Discussion}

We investigated the differences in cup wear and migration between UHMWPE and VEPE in otherwise identical cemented cups up to 5 years. We confirmed that the VEPE cup showed statistically significantly less wear up to 5 years compared with the UHMWPE; however, both cups showed a stable migration pattern. We found that both cups show initial creep during the 1st 3 months, after which head penetration pattern changes and the wear phase gradually takes place (Figures 2 and 3). Furthermore, the wear curve for the VEPE flattened out compared with the UHMWPE, which showed almost linearly increased wear curve. This further strengthens our theory that most of the initial creep takes place during the first 3 months as we have previously reported on other liner types $(14,15)$.

Alpha-tocopherol, vitamin E, is a lipophilic antioxidant compound owing to its phytyl tail, providing favorable interactions with UHMWPE (5). Vitamin E can be incorporated into the UHMWPE in 2 ways. 1 is to blend vitamin $E$ into the UHMWPE powder before consolidation and then cross-link with the use of ionizing radiation. The presence of vitamin $\mathrm{E}$ can, however, reduce the efficiency of cross-linking during the irradiation process. The alternative method is diffusion of the vitamin $\mathrm{E}$ into the UHMWPE following radiation cross-linking and then the cross-linking process is not affected by the presence of vitamin E (16). This method was used on the cups in the current trial and is more widely used today. The vitamin $\mathrm{E}$ is added to the UHMWPE to neutralize the free radicals generated during the irradiation and thermal treatment phase.

The VEPE shows less annual wear than the UHMWPE with an annual wear rate of $0.01 \mathrm{~mm} /$ year compared with 
$0.08 \mathrm{~mm} /$ year for the UHMWPE. Dumbleton et al. proposed acceptable an annual wear threshold of $0.1 \mathrm{~mm} /$ year and both cups are within this threshold (17). In the same review article, the authors proposed that an even safer threshold of $0.05 \mathrm{~mm} /$ year would eliminate osteolysis and the VEPE cup fulfills this requirement as well. These results are consistent with the previously published data on VEPE in uncemented cups $(7,8,18,19)$.

Our results are similar to the 2 studies that have been published on cemented VEPE cups, both of which were done using the same VEPE cup as in our trial, Biomet E1. These studies were conducted similarly to our protocol with early postoperative imaging and the same follow-up intervals. Sköldenberg et al. reported 2-year results with initial head penetration for VEPE after 3 months of $0.22 \mathrm{~mm}$ (SD 0.08) and $0.23 \mathrm{~mm}$ (SD 0.12 ) after 2 years (11). Thoen et al. reported total penetration (Y-axis) of $0.10 \mathrm{~mm}(\mathrm{SD} \mathrm{0.15)}$ at 2 years and $0.17 \mathrm{~mm}$ (SD $0.15)$ at 5 years with a reported annual proximal wear rate of $0.03 \mathrm{~mm} /$ year, thus slightly more than our results (12). Although the wear results for the VEPE cup showed excellent performance, with very low annual wear rate, up to 5 years, there are no definitive signs of superiority of the VEPE compared with HXLPE. However, there is a possibility that the intended effect of vitamin $\mathrm{E}$ infusion of the polyethylene is latent and longer follow-up is needed for the full effect to be observed.

Our secondary outcome was to investigate the possible differences in migration behavior between the cemented cups, as well as clinical outcome. After an initial bedding-in phase where the cup stabilizes, the VEPE cup showed a stable migration pattern while the UHMWPE cup experienced a slight increase in Y-migration up to 5 years but without a statistically significant difference between the cups. This slight increase in Y-translation of the UHMWPE group is explained by the 1 outlier patient who had high migration results. When excluded from the analysis, the curves for both groups were identical from 3 months. When analyzing the migration pattern of the VEPE cup, as Sköldenberg et al. also reported, we see more initial migration of the cup during the first 2 years compared with the UHMWPE cup. Based on their reported 2-year results, Sköldenberg et al. (11) raised concerns regarding potential later loosening of the cemented cup. Our results, however, do not lead us to share the same concerns, as after 2 years the migration curve for the VEPE cup showed a stable migration pattern. This was also reported by Thoen et al. (12). While comparing the differences in wear between the UHMWPE and VEPE it is interesting to note that there seems to be no correlation between the amount of wear generated and the amount of migration of the cup in the acetabulum. This can be explained by both cups being within the acceptable wear threshold of $0.1 \mathrm{~mm} /$ year and therefore not affecting the cup migration.

As previously mentioned, 1 patient in the UHMWPE group had a noticeable radiolucent line in DeLee and Charnley zone 1 on the 1st postoperative radiograph. Compared with the other trial participants, this patient already had higher migration values at 3 months and this continued for the whole follow-up period regarding proximal (Y-translation) and medial (X-translation) cup migration; however, this was not the case for rotational values. It should be noted that the wear values for this patient were not higher compared with other participants in the trial. This patient's HOOS score was very good up to 2 years (100 pts), but the pain score was markedly lower after 5 years ( 65 pts). The cup has not yet been revised, but the patient will be further monitored. We believe that this outlier case is interesting as it already shows the potential predictability value of RSA early on before the onset of clinical symptoms.

The HOOS and EQ5D outcome scores for both the UHMWPE and VEPE groups shows that both cups give good clinical results up to 5 years.

A limitation of our trial is that we compared VEPE cups with UHMWPE cups, and not HXLPE cups. This could have been more relevant as we would then possibly compare the pure effect of the Vitamin E in the production of the VEPE.

In conclusion, our results show that the cemented VEPE cup has a low and stable wear pattern up to 5 years, well below the accepted clinical thresholds, unlike the UHMWPE cup where the $95 \% \mathrm{CI}$ bypasses the clinical threshold for osteolysis. Furthermore, we found that early creep, the deformation phase, seems to gradually end after 3 months. Earlier concerns about VEPE cup stability cannot be confirmed as our results show good cup stability after an initial bedding-in phase.

HB: trial conduction, data analysis, writing of the manuscript. GF, MS, and JT: trial design and conduct, performing surgery, data analysis, and critical revision of the manuscript. VZ: data analysis and critical revision of the manuscript.

Thanks are offered to Håkan Leijon at the RSA laboratory, for computerizing and analyzing the RSA pictures, and research secretary Åsa Björkqvist for keeping track of all the patients, both being at the Department of Orthopedics, Skåne University Hospital, Lund University. The authors would also like to thank Susanna Lövdahl and Tommy Schyman at 4Pharma Ltd for statistical guidance.

Acta thanks Bart G Pijls for help with peer review of this trial.

1. Devane P A, Horne J G, Ashmore A, Mutimer J, Kim W, Stanley J. Highly cross-linked polyethylene reduces wear and revision rates in total hip arthroplasty: a 10-year double-blinded randomized controlled trial. J Bone Joint Surg Am 2017; 99: 1703-14.

2. Hopper R H Jr, Ho H, Sritulanondha S, Williams A C, Engh C A, Jr. Otto Aufranc Award: Crosslinking reduces tha wear, osteolysis, and revision rates at 15-year followup compared with noncrosslinked polyethylene. Clin Orthop Relat Res 2018; 476: 279-90.

3. Oral E, Neils A L, Doshi B N, Fu J, Muratoglu O K. Effects of simulated oxidation on the in vitro wear and mechanical properties of irradiated and melted highly crosslinked UHMWPE. J Biomed Mater Res B Appl Biomater 2016; 104: 316-22. 
4. Kurtz S M, Gawel H A, Patel J D. History and systematic review of wear and osteolysis outcomes for first-generation highly crosslinked polyethylene. Clin Orthop Relat Res 2011; 469: 2262-77.

5. Oral E, Wannomae K K, Hawkins N, Harris W H, Muratoglu O K. Alpha-tocopherol-doped irradiated UHMWPE for high fatigue resistance and low wear. Biomaterials 2004; 25: 5515-22.

6. Salemyr M, Muren O, Ahl T, Bodén H, Chammout G, Stark A, et al. Vitamin-E diffused highly cross-linked polyethylene liner compared to standard liners in total hip arthroplasty: a randomized, controlled trial. Int Orthop 2015; 39: 1499-1505.

7. Galea V P, Connelly J W, Shareghi B, Kärrholm J, Sköldenberg $\mathbf{O}$, Salemyr M, et al. Evaluation of in vivo wear of vitamin E-diffused highly crosslinked polyethylene at five years: a multicentre radiostereometric analysis study. Bone Joint J 2018; 100-B: 1592-9.

8. Galea V P, Rojanasopondist P, Laursen M, Muratoglu O K, Malchau H, Bragdon C. Evaluation of vitamin E-diffused highly crosslinked polyethylene wear and porous titanium-coated shell stability: a sevenyear randomized control trial using radiostereometric analysis. Bone Joint J 2019; 101-b: 760-7.

9. Shareghi B, Johanson P E, Kärrholm J. Wear of vitamin e-infused highly cross-linked polyethylene at five years. J Bone Joint Surg Am 2017; 99: 1447-52.

10. Lindalen E, Thoen P S, Nordsletten L, Høvik Ø, Röhrl S M. Low wear rate at 6-year follow-up of vitamin E-infused cross-linked polyethylene: a randomised trial using 32- and 36-mm heads. Hip Int 2019; 29: 355-62.

11. Sköldenberg O G, Rysinska A D, Chammout G, Salemyr M, Mukka S S, Bodén H, et al. A randomized double-blind noninferiority trial, evaluating migration of a cemented vitamin E-stabilized highly crosslinked component compared with a standard polyethylene component in reverse hybrid total hip arthroplasty. Bone Joint J 2019; 101-B: 1192-8.
12. Thoen P S, Nordsletten L, Pripp A H, Röhrl S M. Results of a randomized controlled trial with five-year radiostereometric analysis results of vitamin E-infused highly crosslinked versus moderately crosslinked polyethylene in reverse total hip arthroplasty. Bone Joint J 2020; 102-b: 1646-53.

13. Valstar E R, Gill R, Ryd L, Flivik G, Borlin N, Kärrholm J. Guidelines for standardization of radiostereometry (RSA) of implants. Acta Orthop 2005; 76: 563-72.

14. Bergvinsson $\mathbf{H}$, Sundberg M, Flivik G. Polyethylene wear with ceramic and metal femoral heads at 5 years: a randomized controlled trial with radiostereometric analysis. J Arthroplasty 2020; 35(12): 3769-76. doi: 10.1016/j.arth.2020.06.057.

15. Bergvinsson H, Zampelis V, Sundberg M, Flivik G. Highly crosslinked polyethylene still outperforms conventional polyethylene in THA: 10-year RSA results. Acta Orthop 2021; 92(5): 568-74. doi: 10.1080/17453674.2021.1932140: 1-7.

16. Oral E, Wannomae K K, Rowell S L, Muratoglu O K. Diffusion of vitamin $\mathrm{E}$ in ultra-high molecular weight polyethylene. Biomaterials 2007; 28: 5225-37.

17. Dumbleton J H, Manley M T, Edidin A A. A literature review of the association between wear rate and osteolysis in total hip arthroplasty. J Arthroplasty 2002; 17: 649-61.

18. Kjærgaard K, Ding M, Jensen C, Bragdon C, Malchau H, Andreasen C M, et al. Vitamin E-doped total hip arthroplasty liners show similar head penetration to highly cross-linked polyethylene at five years: a multiarm randomized controlled trial. Bone Joint J 2020; 102-b: 1303-10.

19. Rochcongar G, Buia G, Bourroux E, Dunet J, Chapus V, Hulet C. Creep and wear in vitamin e-infused highly cross-linked polyethylene cups for total hip arthroplasty: a prospective randomized controlled trial. J Bone Joint Surg Am 2018; 100: 107-14.

\section{Supplementary data}

Table 2. Precision values of the cup wear and migration analysis. The value given represents the smallest migration that is considered statistically significant and is based on 2 SD of the error obtained. This therefore corresponds to the $95 \%$ confidence limit

\begin{tabular}{lrrc}
\hline Axis & $\mathrm{n}$ & Mean $(\mathrm{SD})$ & Precision values \\
\hline Wear: Y-translation $(\mathrm{mm})$ & 48 & $0.00(0.04)$ & 0.09 \\
Cup translation $(\mathrm{mm})$ & & & \\
X & 53 & $0.01(0.05)$ & 0.09 \\
Y & 53 & $-0.01(0.04)$ & 0.08 \\
Z & 53 & $0.01(0.09)$ & 0.18 \\
Cup rotation $\left(^{\circ}\right)$ & & & \\
X & 53 & $0.24(0.22)$ & 0.43 \\
Y & 53 & $0.00(0.25)$ & 0.48 \\
Z & 53 & $0.02(0.13)$ & 0.48 \\
\hline
\end{tabular}




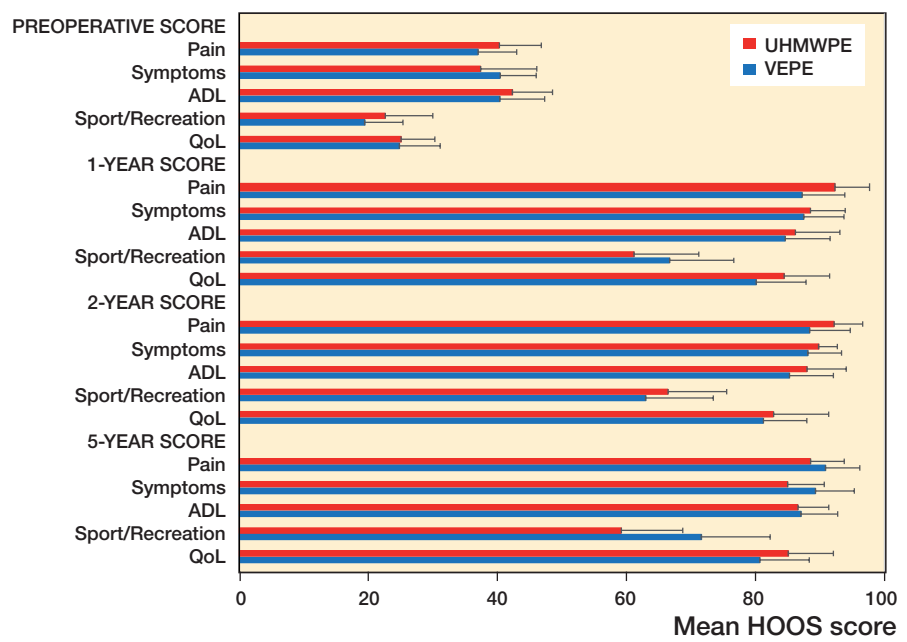

Figure 6. HOOS questionnaire outcome. HOOS outcome measures: Pain; Symptoms including stiffness and range of motion; Activity limitations - daily living (ADL); Sport and Recreation Function (Sport/Recreation); and Hip-Related Quality of Life (QoL). A score of 0 indicates poor function/high number of symptoms, a score of 100 indicates excellent function/low number of symptoms.

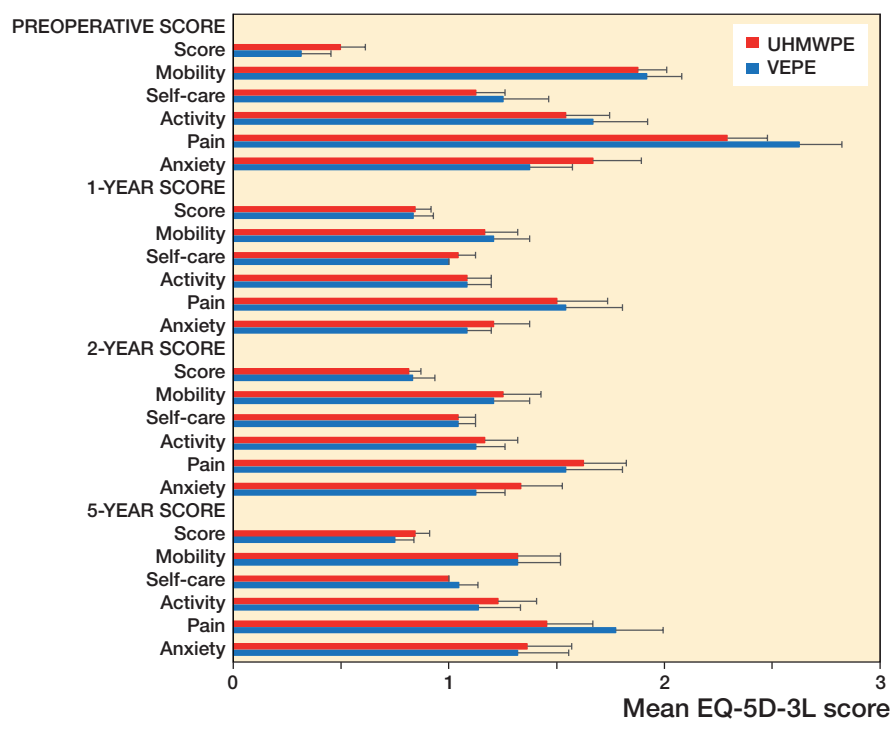

Figure 7. EQ5D questionnaire outcome. EQ5D measures: EQ5D Score, EQ5D Mobility, EQ5D Self-care, EQ5D Activity, EQ5D Pain, EQ5D Anxiety. Patients' responses are coded as a number $(1,2$, or 3$)$ that corresponds to the respective level of severity: 1 indicates no problems, 2 some problems, and 3 extreme problems. 